\title{
The Reliability Study of Ram BOP Seals of Temperature snubbing
}

\author{
Jiaqi Jin ${ }^{1, a}$, Xianrong Wang ${ }^{2, b}$, Yuan Liang ${ }^{3, c}$ and Wei Zhou ${ }^{4, d}$ \\ ${ }^{1,3,4}$ Schoolof mechanical engineering, Shenyang University of Technology, Shenyang, PR China \\ ${ }^{2}$ Institution of drilling tool, Liao He oilfield of CNPC, Panjin, PR China \\ ajinjq612@126.com, c315078020@qq.com
}

\begin{abstract}
In order to study the safety and reliability of the seal ram BOP, this article analyzes the structure and principles of ram BOP, draws the reason of seals failure by analyzing the forces of sealant core; uses accurate simulation on plastic core by ANSYS Software and then draws that morph mainly occurs in front of the plastic core. After the scene several simulation experiments, the damage is consistent with the results of finite element analysis.
\end{abstract}

\section{Introduction}

With the further development of oil and gas fields, oil and water wells maintenance have become more and more frequent. Conventional operations generally use high-density killing hydraulic well or using blowout means to reduce the well pressure to conduct operations, high-density killing fluid not only the high cost, long time, and will plug the underground water channels, affecting oil production and water injection effect ${ }^{[1]}$. If a blowout buck, will not only significantly reduce the formation energy, bring inestimable loss to follow-up production, at the same time, also can cause a lot of environmental pollution. The blowout preventer seal system is the core device of snubbing system equipment, sealing performance is directly related to the effectiveness and success of the job under pressure.

\section{System function and structural principles}

In the high temperature and pressure operation,using ram BOP workover equipment can solve technical problems of three areas:

\footnotetext{
c Corresponding author: 463494796@qq.com
}

a. Fast switching action, safe, reliable and easy to use, in exceptional cases, can cut off the pipeline;

b. In the process of construction operation, realized the tubing, casing annulus dynamic seals and internal clogging of column, through the manifold that shell bypass outlet connect conduct the mud circulation, well pressure operation;

c. The lower pipe column process can overcome the pressure in the well on the string of jacking force, to achieve safety and no pollution pressure construction.

The overall structure consists of housing, side door, sealing ram assembly, piston, cylinder, cylinder head, locking shaft, shields, etc.

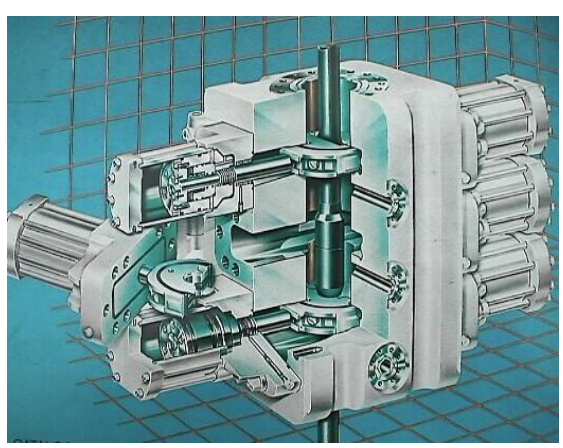

Figure 1. BOP system structure 


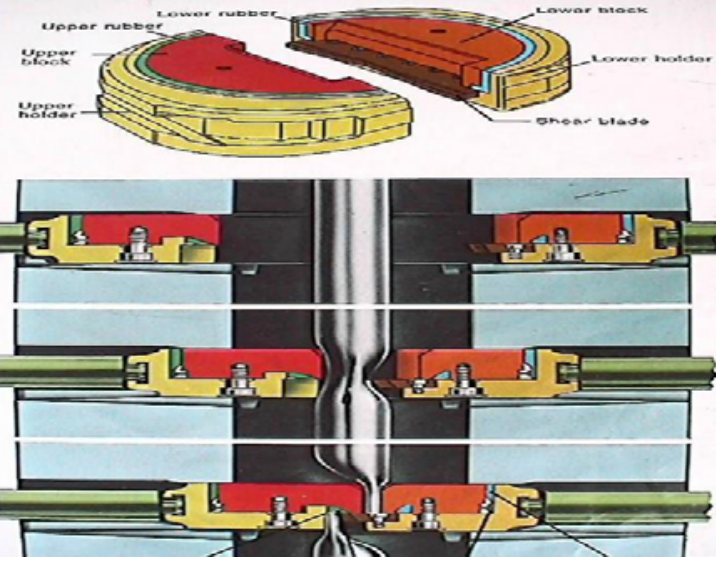

Figure 2. The three gate BOP principle diagram

Shutter switch is controlled by hydraulic valve control system, when the high-pressure oil of hydraulic control system into both sides of the hydraulic cylinder ram closed chamber,will push the piston to drive the gate shaft and both sides of flashboard assembly along the shell of a flashboard cavity respectively move to the wellhead center and achieve plugging. When the high-pressure oil of hydraulic control system into both sides of the hydraulic cylinder ram open cavity,will push the piston to drive the gate shaft and bothsides of flashboard assembly to leave the center of the well head and open the wellhead. The sealing process of the gate is divided into two steps: first, under the effect of hydraulic oil, the gate shaft push the front gate sealant core so that the front gate sealant core is extruded and deformed,the Interference between top of sealant core and the shell compress top of sealant core and then form initial sealing; second, when there is pressure in the well, well pressure pushing top of gate sealant core from gate rear make the front gate sealant core further extruded and deformed, at the same time the well pressure push the gate floating and snapping the housing sealing surface, thereby forming a reliable seal, that is the role of well pressure to help seal[2].

\section{Sealant core failure analysis}

When the gate rubber core sealing pipe column, the circular arc surface of rubber core maintain sufficient contact pressure with pipe column diameter, the rubber core is extruded and deformed, according to the wear delamination theory when sliding friction at low speed, the total amount of wear between hard surface and soft surface is proportional to positive pressure and sliding distance. Therefore, when working with pressure, The higher liquid pressure of injection wells, plastic core sealing surface more susceptible to wear, until they lose the sealing contact pressure that pressure operation condition should have, thus resulting in seal failure.

From the actual working conditions of ram BOP plugging, considering the role of well pressure on the front part of the rubber paraboloid, obviously, the actual deformation of free surfaces can be obtained according to the elastic mechanics knowledge, more accurate calculation of finite strain expressions as follows:

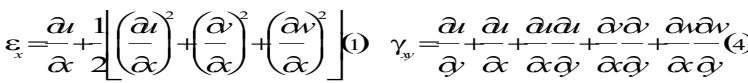

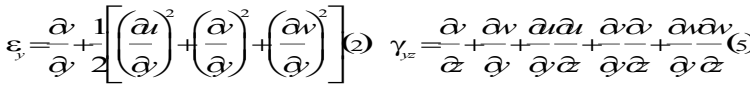

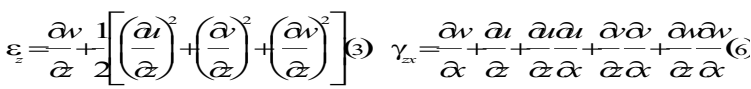

In the formula, $\varepsilon_{x}, \varepsilon_{y}, \varepsilon_{z}$ and $\gamma_{x y}, \gamma_{z y}, \gamma_{z x}$ represent the normal strain and shear strain respectively, $u, v, w$ are the direction of displacement of the three coordinate axes[3]. According to the statistical theory of rubber elasticity, obtain the stress-strain special relationship of volume before and after deformation, according to the boundary condition, actual deformation of the front of the rubber can be solved in theory[4].

\section{Finite element analysis}

Analyzing plastic core top model and doing finite element network partitioning by Marc software[5]. In addition to the front end face of the node, $z$ displacement is zero of other nodes; $\mathrm{x}, \mathrm{y}, \mathrm{z}$ displacement of some nodes is zero that contact with ram body arc groove; $\mathrm{x}$ displacement on both sides of the nodes is zero. The inner rubber core of the model is sealed with rubber material, elastic modulus: $7.8 \mathrm{E}+0.6 \mathrm{PA}$, poisson's ratio: 0.47PA, the contact surface is a hexahedron consists of 19948 units, 93259 nodes.

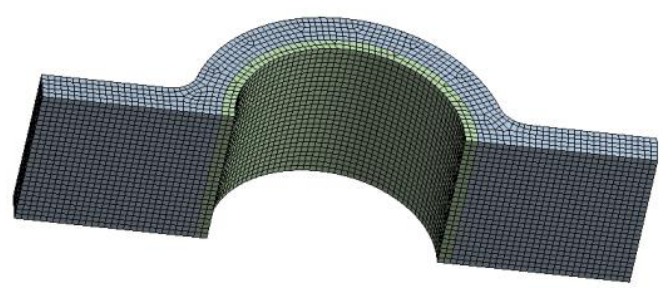

Figure 3. Seal mesh partition 


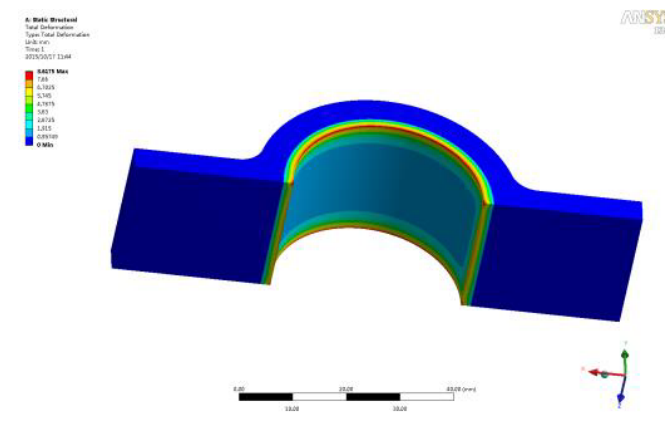

Figure 4. Seal the whole stress

As we can see from Figure 3and 4, plastic deformation occurs mainly in the front part of the core, rubber around the ribs which in the middle of the four skeleton of plastic core front portion have a greater deformation, this shows where the rubber is extruded,which is the main source of the closed drill pipe rubber core arc surface of the sealing gap. After the rubber is extruded from the skeleton, and then squeezed by string, produce $\mathrm{z}$ displacement, the rubber extruded due to limitations of backbone bear tensile stress besides suffering extruded tube column stress. So it is easy to make plastic core destruction.

\section{Trial production of 7 "wellhead equipment simulation test}

To suppress to the annulus using high-pressure pump, BOP were closed in each group, check the sealing condition, results as shown in Table 1.

Table 1. The Results of Field Experiments

\begin{tabular}{|c|c|c|c|}
\hline Semi rams & $\begin{array}{c}\text { Test } \\
\text { pressure } \\
\text { Mpa }\end{array}$ & Frequency & Test results \\
\hline $\begin{array}{c}\text { Full closure } \\
\text { gate }\end{array}$ & 21 & 3 & $\begin{array}{c}10 \text { min drop }<0.7 \\
\text { MPa No leakage }\end{array}$ \\
\hline $\begin{array}{c}\text { Shear ram } \\
\text { MPa No leakage }\end{array}$ \\
\hline The ring & 21 & 3 & $\begin{array}{c}14 \text { MpaControl } \\
\text { pressure cut } 114 \\
\text { Insulated pipe }\end{array}$ \\
\hline $\begin{array}{c}\text { Full closure } \\
\text { gate }\end{array}$ & 21 & 3 & $\begin{array}{c}10 \text { min drop }<0.7 \\
\text { MPa No leakage }\end{array}$ \\
\hline Under & 21 & 3 & $\begin{array}{c}\text { 10min drop }<0.7 \\
\text { MPa No leakage }\end{array}$ \\
\hline Circular & 21 & 3 ma No leakage \\
\hline
\end{tabular}

The above table shows: semi rams, full closure gate, shear ram, the ring, full closure gate, under circular blowout preventer system all have no leakage, at this point the rubber core still has the sealing capability.

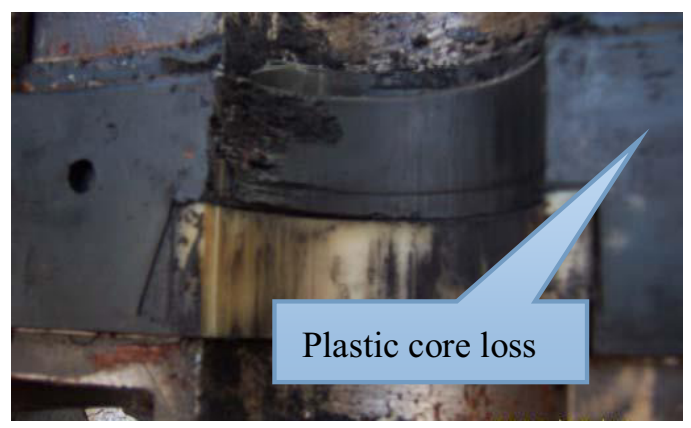

Figure 5. Sealants core fatigue test

As can be seen from Figure 5, the transition part appear serious abrasion between front plane and circular surface of plastic core, damage is consistent with the finite element analysis results.

\section{References}

1. Yi Xin Tang. Snubbing from the drilling equipment and technology $[\mathrm{J}]$. Drilling \& Production Technology,1995,18(11):122-128.

2. Yu Zhang, Shu ren Zhang. New breakthrough of sealing technology:Adjustable seal $[\mathrm{J}]$. Hydraulic and pneumatic seals , 1999 ( 6) : 42-43.

3. Bei chen Liu, Hong sen Lu, Elastic mechanics [M]. Metallurgical industry press, 1979

4. P.K Kerry Frey,A.R Payne,Theory and Practice that rubber used in engineering,Chemical industry press, 1985.

5. Changfeng Zhou,Jianrun Zhang. Rubber buffer finite element analysis [J]. Elastomer2004, 14 (1) : $39-42$.

Fund Project:Research on Key Technology of

Truck-mounted steam engine Flooding with hing temperature snubbing workover.

(2013020087-301) 